\title{
Editorial
}

\section{Solar Energy and PV Systems in Smart Cities}

\author{
Daniele Menniti, ${ }^{1}$ Angel A. Bayod-Rújula, ${ }^{2}$ Alessandro Burgio, ${ }^{1}$ Diego A. L. García, ${ }^{3}$ and \\ Zbigniew Leonowicz ${ }^{4}$
}

${ }^{1}$ University of Calabria, Rende, Italy

${ }^{2}$ University of Zaragoza, Zaragoza, Spain

${ }^{3}$ University of Huelva, Huelva, Spain

${ }^{4}$ Wroclaw University of Technology, Wrocław, Poland

Correspondence should be addressed to Daniele Menniti; daniele.menniti@unical.it

Received 23 April 2017; Accepted 23 April 2017; Published 9 July 2017

Copyright ( 2017 Daniele Menniti et al. This is an open access article distributed under the Creative Commons Attribution License, which permits unrestricted use, distribution, and reproduction in any medium, provided the original work is properly cited.

A PV system on the rooftop is an easy and cost-effective way which allows consumers to independently meet a part of own electricity need. From an economic and financial perspective, consumers reduce the electricity bill and save money. These savings can be reinvested in actions aimed at the increase in energy efficiency, so triggering a worthy process of improvement. From a social perspective, consumers exploit renewable energy sources, so contributing to the environmental preservation by reducing the greenhouse gas emissions.

The opportunities described above are evidently reserved to those users who have ample space for installing a PV system; on the contrary, users who live in apartment buildings in the cities are excluded. For the latter category, smart cities may represent a solution. Indeed, smart cities can offer to all citizen the same opportunities in the pair of renewable energy source exploitation and sustainable development. As an example, citizens living in a rural area have large roofs; their existing or new PV plants can be oversized with respect to the local demand, and the overgeneration may serve citizens living in a built-up area. Although very simple, this initiative brings citizens close to each other and relevantly joins them in a process of social development.

In this frame, the purpose of this special issue is to stimulate the development of feasible and new idea, models, mechanisms, techniques, pathways, and policies.

As an introduction to the topics, PV generation is the subject of the paper authored by W. Hou et al.; in the paper, the authors present a novel maximum power point tracking algorithm based on glow-worm swarm optimization for photovoltaic systems. Similarly, R.-M. Chao et al. present a multicore particle swarm optimization for maximum power point tracking of a distributed photovoltaic system under partially shading condition. In PV generation topic, E. Blasius et al. present a paper and discuss the utilisation of PV systems for electric vehicle (EV) charging for transportation requirements of smart cities. Because low and high irradiation seasons influence the PV power generation and the EV charging demand varies over the year and correlated to weather conditions, the authors conclude that the sizing and performance of supportive storage devices should be evaluated in a statistical manner, using long-period observations. PV generation is also the subject of the paper authored by G. Li and Y. Jin; in place of conventional crystalline modules, the authors focus their attention on a Fresnel solar concentrator and propose an optical simulation and experimental verification of a Fresnel solar concentrator with a new hybrid second optical element.

The combination of PV modules and thermal modules is the point of discussion in the paper authored by A. Y. A. Oyieke and F. L. Inambao. The authors study the performance characterization of a hybrid flat-plate vacuum-insulated photovoltaic/thermal solar power module in subtropical climate; the authors conclude that these hybrid modules present superior thermal characteristics compared to conventional $\mathrm{PV} / \mathrm{T}$ with an air insulation layer.

In the paper authored by O. H. Yuregir and C. Sagiroglu, the validation of solar energy as a strategic key in investment planning via comparative data mining methods is faced; the 
authors further deepen the study with an expanded example within the cities of Turkey.

Three research contributions further enrich this special issue by addressing three particular themes. Y. Xu et al. author the first contribution; the authors discuss the energy conversion and transmission characteristic analysis of the ice storage air conditioning system driven by the distributed photovoltaic energy system. M. Yahya authors the second contribution and analyses the performance of a solarassisted fluidized bed dryer integrated biomass furnace with and without heat pump for drying of paddy. K. Wang et al. author the last of these three contributions; they propose the optimizing operation of exhaust air heat recovery and solar energy-combined thermal compensation system for a ground-coupled heat pump.

A review paper rounds off this special issue; A. A. Bayod-Rújula et al. illustrate recent developments of integrated PV-battery systems and related feed-in tariff policies.

\section{Acknowledgments}

We would like to express our appreciation to all the authors and reviewers, for their contributions and comments, in making this special issue possible.

Daniele Menniti Angel A. Bayod-Rújula Alessandro Burgio Diego A. L. García Zbigniew Leonowicz 

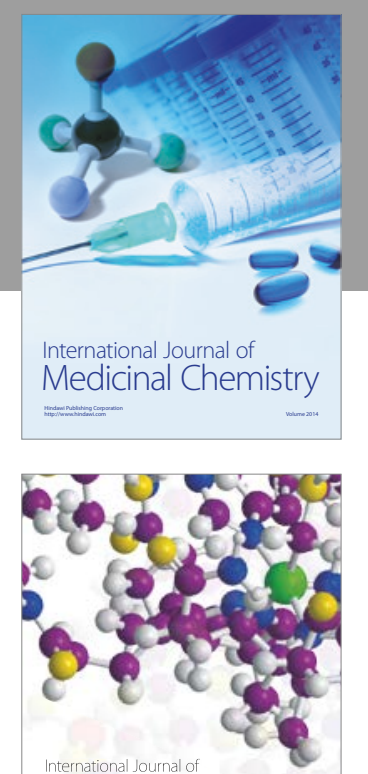

Carbohydrate Chemistry

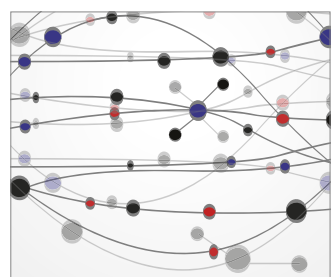

The Scientific World Journal
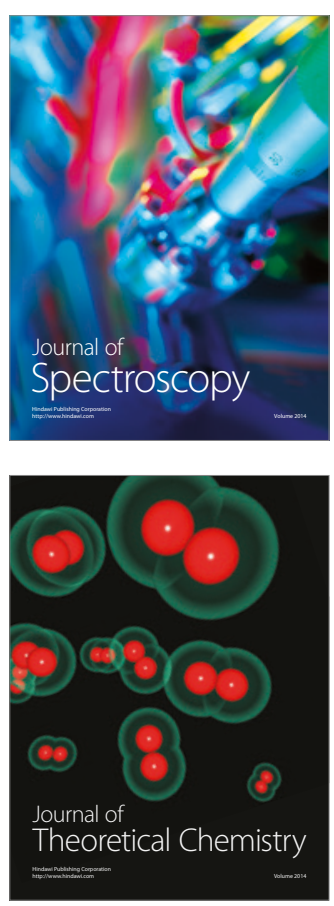
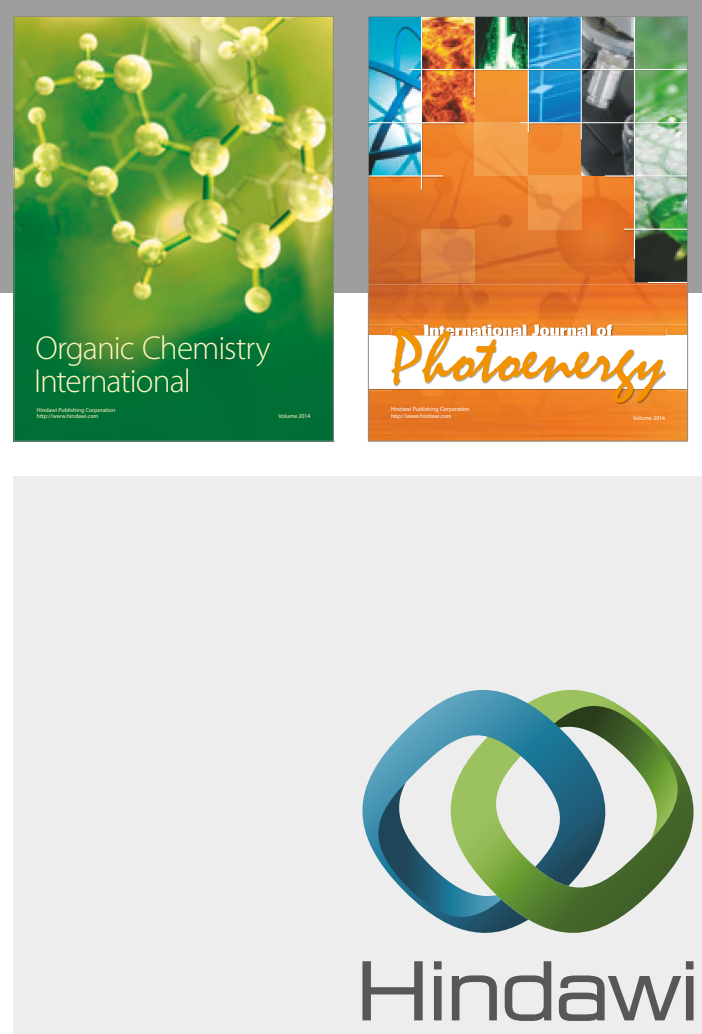

Submit your manuscripts at

https://www.hindawi.com

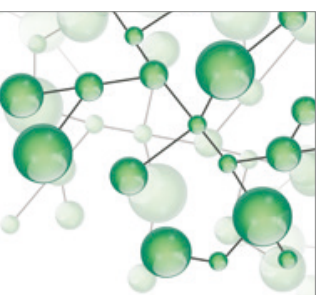

International Journal of

Inorganic Chemistry

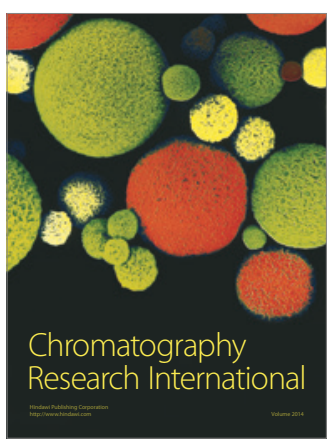

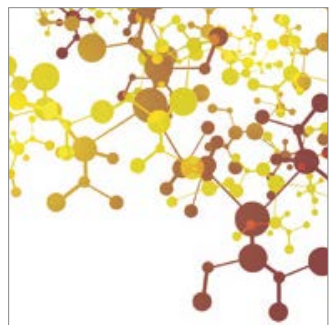

Applied Chemistry
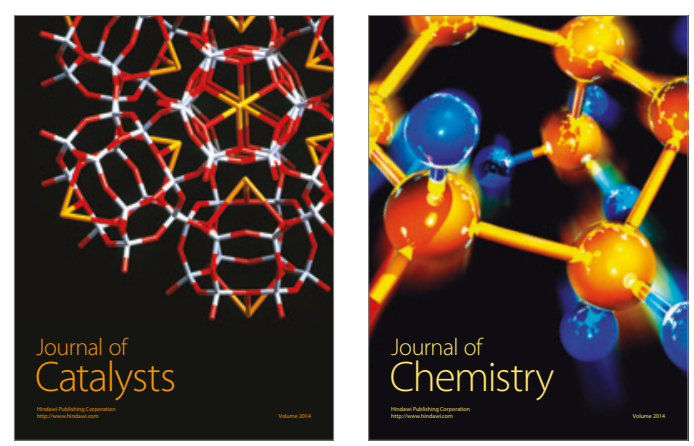
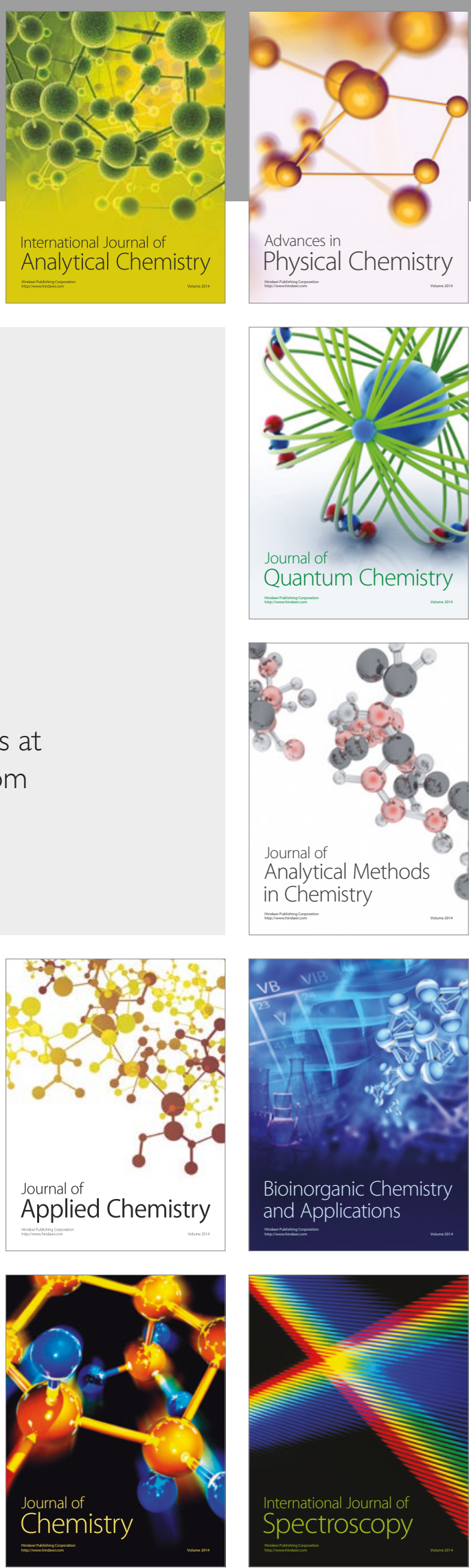